\title{
Suppression of HIF-1 $\alpha$ expression and radiation resistance in acute hypoxic conditions
}

\author{
TAKAHIRO OIKE $^{1}$, YOSHIYUKI SUZUKI $^{1}$, WAEL AL-JAHDARI $^{1}$, ABDULELAH MOBARAKI $^{1}$, \\ JUN-ICHI SAITOH ${ }^{2}$, KOHTA TORIKAI $^{2}$, KATSUYUKI SHIRAI ${ }^{1}$ and TAKASHI NAKANO ${ }^{1}$ \\ ${ }^{1}$ Department of Radiation Oncology, Gunma University Graduate School of Medicine; \\ ${ }^{2}$ Gunma University Heavy Iron Medical Center, Gunma 371-8511, Japan
}

Received August 5, 2011; Accepted October 3, 2011

DOI: $10.3892 / \mathrm{etm} .2011 .373$

\begin{abstract}
Recently, it has become clear that acute hypoxia affecting radioresistance exists widely in tumor tissues. Concurrently, hypoxia-inducible factor- $1 \alpha$ (HIF- $1 \alpha)$ is recognized as an essential transcriptional factor, enabling cells to survive through hypoxia. However, it is unclear as to whether HIF-1 $\alpha$ plays a direct role in the radioresistance caused by acute hypoxia. Therefore, in this study, we investigated the in vitro response of the human lung adenocarcinoma cell line, A549, to ionizing radiation in an experimental model that imitates acute hypoxia in the presence and absence of HIF-1 $\alpha$ expression, using the HIF- $1 \alpha$ inhibitor 5-[1-(phenylmethyl)-1H-indazol-3-yl]-2-furanmethanol (YC-1). Cells were treated with or without $10 \mu \mathrm{M}$ YC-1 for $2 \mathrm{~h}$. Cells were exposed to either $95 \% \mathrm{~N}_{2}$ and $5 \% \mathrm{CO}_{2}$ (hypoxic condition of $<0.1 \mathrm{mmHg}$ ) or atmospheric air (normoxic condition) for $1 \mathrm{~h}$, and irradiated with 2, 5 and $10 \mathrm{~Gy}$. Western blot analysis revealed that, without YC-1, cells exposed to hypoxic conditions expressed increased levels of HIF-1 $\alpha$ compared with those exposed to normoxic conditions. Under hypoxic conditions, HIF-1 $\alpha$ expression was suppressed by YC-1 to the same extent as that observed in cells exposed to normoxic conditions without YC-1. Clonogenic survival assay revealed that under hypoxic conditions there was no significant difference between the surviving fraction of cells treated with YC-1 and without YC-1 at any dose point examined. The oxygen enhancement ratio at $10 \%$ surviving fraction was calculated as 2.7 and 2.6 in the presence and the absence of YC-1, respectively. These results indicate that HIF-1 $\alpha$ itself is not an immediate cause of acute hypoxia-induced radioresistance in A549 cells.
\end{abstract}

Correspondence to: Dr Yoshiyuki Suzuki, Department of Radiation Oncology, Gunma University Graduate School of Medicine, 3-39-22, Showa-machi, Maebashi, Gunma 371-8511, Japan

E-mail: syoshi@med.gunma-u.ac.jp

Key words: hypoxia-inducible factor- $1 \alpha, \mathrm{YC}-1$, radiation resistance, acute hypoxia

\section{Introduction}

Hypoxia in the microenvironment of tumors is well recognized as one of the major factors affecting resistance against radiation therapy (1-4). In the clinical setting, a number of investigators have proven the existence of hypoxic cells in human cancers by directly measuring intratumoral oxygen partial pressure $\left(\mathrm{pO}_{2}\right)$ using special electrodes (5-7). We have also previously reported that low pretreatment intratumoral $\mathrm{pO}_{2}$ correlates with poor clinical outcome in cervical cancer treated with photon therapy (7).

It is recognized that hypoxia in tumors may result from two quite different mechanisms, namely 'acute hypoxia' and 'chronic hypoxia' (8). Acute hypoxia is the result of the abrupt temporary closing of a tumor blood vessel owing to the malformed vasculature of the tumor, which lacks smooth muscle functionality and often has an incomplete endothelial lining and basement membrane (9). Meanwhile, chronic hypoxia arises in regions distant from the blood vessels owing to the limited diffusion distance of oxygen through solid and massive tumor tissues. Although the compositional contribution of acute hypoxia to total hypoxia in tumor tissues has been considered to be low $(10,11)$, recently, Cárdenas-Navia et al proved the pervasive presence of fluctuating $\mathrm{pO}_{2}$ in rat tumors (12), indicating that acute hypoxia is a more common phenomenon in tumor tissues than previously presumed. In clinical practice, fractionated radiation therapy, which leads to tumor reoxygenation is considered to be an effective method for killing cancer cells under conditions of chronic hypoxia (8). However, therapeutic significance of acute hypoxia in radiation therapy remains unclear.

Hypoxia-inducible factor- $1 \alpha$ (HIF-1 $\alpha$ ) is considered to be an essential transcriptional factor, which mediates a number of physiological responses in tumor cells under hypoxic conditions $(13,14)$. HIF-1 $\alpha$ is synthesized under normoxia but undergoes rapid ubiquitination and proteosomal degradation (15). Under hypoxia, HIF-1 $\alpha$ stabilizes, translocates to the nucleus and dimerizes with HIF-1 $\beta$ forming the heterodimer, HIF-1 $(16,17)$. HIF-1 then binds to hypoxia-responsive elements of genes mediating physiological responses to hypoxia. As a result, HIF-1 $\alpha$ promotes cell survival by increasing glucose transport, converting cellular metabolism to the obligatory glycolytic system and also inducing vascular endothelial growth 
factor (VEGF) expression, which leads to angiogenesis (18). In clinical specimens, high HIF-1 $\alpha$ expression levels correlate with poor responses to radiation therapy and chemotherapy in several studies (19-23). However, the exact role of HIF-1 $\alpha$ in tumor resistance to radiation therapy under hypoxia has not yet been fully elucidated. Moreover, to the best of our knowledge, previous studies investigating the relationship between HIF-1 $\alpha$ expression and hypoxia-induced radioresistance do not take into account the different circumstances between acute and chronic hypoxia.

Taking all these things into consideration, the present study was conducted to investigate whether HIF-1 $\alpha$ has a direct fundamental role in the radioresistance induced by acute hypoxia. The in vitro response of the human lung adenocarcinoma cell line, A549, to ionizing radiation was examined in an experimental model that imitates acute hypoxia with or without HIF-1 $\alpha$ expression using the well known HIF-1 $\alpha$ inhibitor, 5-[1-(phenylmethyl)-1H-indazol-3-yl]-2-furanmethanol (YC-1).

\section{Materials and methods}

Cell culture and drugs. The human lung adenocarcinoma cell line, A549, was generously provided from the Cell Resources Center for Biomedical Research, Institute of Development, Aging and Cancer, Tohoku University (Sendai, Japan). A549 was cultured in RPMI-1640 (Invitrogen, Carlsbad, CA, USA) supplemented with $10 \%$ fetal bovine serum (Biowest, Miami, FL, USA) and 5\% penicillin-streptomycin (Gibco, Grand Island, NY, USA) in a humidified incubator at $37^{\circ} \mathrm{C}$ and $5 \% \mathrm{CO}_{2}$. YC-1 was purchased from Cayman Chemicals (Gruenberg, Germany), resuspended in dimethyl sulfoxide (DMSO) at a concentration of $10 \mu \mathrm{g} / \mathrm{ml}$ and stored at $-20^{\circ} \mathrm{C}$.

Western blot analysis for measuring expression of HIF-1 $\alpha$. Western blot analysis was performed to assess the effect of YC-1 on HIF-1 $\alpha$ suppression. Cultured A549 cells were trypsinized, counted, seeded to glass dishes at a concentration of $1 \times 10^{4}$ cells in $2 \mathrm{ml}$ of medium (RPMI-1640 with $10 \%$ fetal bovine serum and 5\% penicillin-streptomycin) and allowed to attach overnight at $37^{\circ} \mathrm{C}$. The medium was replaced the following day by fresh medium with $10 \mu \mathrm{M}$ YC-1 and incubated for $2 \mathrm{~h}$ at $37^{\circ} \mathrm{C}$. The cells were exposed to hypoxic conditions of $<0.1 \mathrm{mmHg}$ for 1 and $24 \mathrm{~h}$, as an experimental model of acute and chronic hypoxia, respectively. For exposure of the cells to radiation under hypoxic conditions, a hypoxic chamber with an atmospheric gas-concentration control apparatus designed by Furusawa $e t$ al was used (24). Briefly, for exposure under hypoxic conditions, the glass dishes containing the cells were placed in the steel chamber. The chamber was flushed with

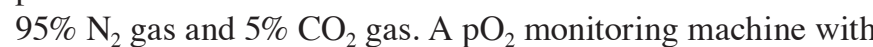
electrodes (UOE-04T, Unique Medical, Tokyo) placed into the glass dishes was used for real-time monitoring of the $\mathrm{pO}_{2}$ level.

The cells were washed with phosphate-buffered saline, scraped from the culture plates, centrifuged briefly and then solubilized into the mixture of RIPA lysis buffer (Millipore, Billerica, MA, USA), $1 \%$ phosphatase inhibitor cocktail 1 (Sigma-Aldrich, St. Louis, MO, USA), phosphatase inhibitor cocktail 2 (Sigma-Aldrich) and protease inhibitor cocktail set 3 (Merck, Darmstadt, Germany). Equal amounts of protein

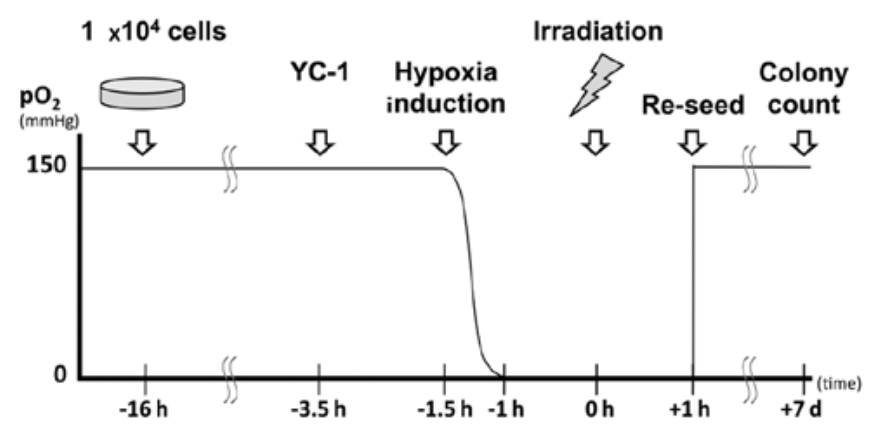

Figure 1. Schematic representation of clonogenic survival assay. h, hour; d, day; YC-1, 5-[1-(phenylmethyl)-1H-indazol-3-yl]-2-furanmethanol; $\mathrm{pO}_{2}$, oxygen partial pressure.

from the lysates were fractionated on $12.5 \%$ polyacrylamide gels (Bio-Rad Japan, Tokyo, Japan) and then transferred to Pure Nitrocellulose Membranes (Bio-Rad Japan). The Western blots were probed with an antibody directed against HIF-1 $\alpha$ (BD Transduction Laboratories, Lexington, KY, USA) and actin (Chemicon International Inc., Temecula, CA, USA) and incubated with secondary antibodies conjugated to horseradish peroxidase (Dako, Glostrup, Denmark). The enhanced chemiluminescence (ECL) Western Blot Detection System (GE Healthcare Japan, Tokyo, Japan) was used for protein detection.

Clonogenic survival assay of irradiated cells. A clonogenic survival assay was performed to assess the effect of HIF-1 $\alpha$ suppression on the radiosensitivity of A549 cells under acute hypoxia. A schematic representation of this assay is described in Fig. 1. Cultured A549 cells were trypsinized, counted, seeded to glass dishes at a concentration of $1 \times 10^{4}$ cells in $2 \mathrm{ml}$ of medium and allowed to attach overnight at $37^{\circ} \mathrm{C}$. The medium was replaced the following day by fresh medium with or without $10 \mu \mathrm{M}$ YC-1 and incubated for $2 \mathrm{~h}$ at $37^{\circ} \mathrm{C}$. $\mathrm{pO}_{2}$ levels reached $<0.1 \mathrm{mmHg}$ approximately $30 \mathrm{~min}$ following induction of hypoxia. The cells were maintained under the hypoxic condition of $<0.1 \mathrm{mmHg}$ for $1 \mathrm{~h}$, irradiated with 2, 5 and 10 Gy of 4 MV X-ray (Elekta Synergy, Elekta $\mathrm{AB}$, Stockholm, Sweden), and maintained under the same hypoxic condition for a further hour. As a control, cells in the chamber were irradiated 2, 5 and 10 Gy under atmospheric air and exposed under hypoxic conditions for $2 \mathrm{~h}$ in order to match the condition of the case and the control with regard to the effect of hypoxia on cell survival.

Cultured dishes were then removed from the chamber. The cells were trypsinized, counted, re-seeded into 6-well plates at a specified number at in least triplicate with fresh medium, and incubated at $37^{\circ} \mathrm{C}$ for 7 days under normoxic conditions to enable colony formation. Cells were stained with crystal violet (Sigma-Aldrich) solution (2\%) in 100\% ethanol and colonies of at least 50 cells were counted. Plating efficiency was calculated as the ratio of the number of colonies formed to the number of cells seeded in the absence of radiation.

The $\mathrm{D}_{10}$ value, which is a survival parameter representing a radiation dose required to reduce the surviving fraction to $10 \%$, was calculated from each survival data set by a curve fitting method using the linear-quadratic (LQ) model: 
Table I. Surviving fraction of A549 cells obtained from clonogenic survival assay.

\begin{tabular}{lcccc}
\hline & 2 Gy & 5 Gy & 10 Gy & OER \\
\hline Normoxic conditions without YC-1 & $0.55 \pm 0.14$ & $0.17 \pm 0.10$ & $0.00012 \pm 0.00017$ & 5.3 \\
Hypoxic conditions with YC-1 & $0.71 \pm 0.24^{\mathrm{a}}$ & $0.63 \pm 0.31^{\mathrm{c}}$ & $0.24 \pm 0.09^{\mathrm{c}}$ & - \\
Hypoxic conditions without YC-1 & $0.79 \pm 0.20^{\mathrm{b}}$ & $0.74 \pm 0.11^{\mathrm{c}}$ & $0.26 \pm 0.02^{\mathrm{c}}$ & 14 \\
\hline
\end{tabular}

a, b, ${ }^{c}$ Significantly different from the corresponding values obtained under normoxic conditions without $\mathrm{YC}-1\left({ }^{\mathrm{a}} \mathrm{p}<0.05,{ }^{\mathrm{b}} \mathrm{p}<0.01,{ }^{\mathrm{c}} \mathrm{p}<0.001\right)$. $\mathrm{D}_{10}$, dose required to obtain $10 \%$ surviving fraction; OER, oxygen enhancement ratio. Each value represents an average surviving fraction with the standard deviation. YC-1, 5-[1-(phenylmethyl)-1H-indazol-3-yl]-2-furanmethanol.

$\mathrm{SF}=\exp \left(-\alpha \mathrm{D}-\beta \mathrm{D}^{2}\right)$; where $\mathrm{SF}$ is the surviving fraction and $\mathrm{D}$ is the dose. The oxygen enhancement ratio (OER) was calculated as the ratio of the $\mathrm{D}_{10}$ value obtained under hypoxic conditions to that obtained in the control condition.

Statistical analysis. Statistical analysis was performed by StatMateIII Version 3.17 (ATMS, Tokyo, Japan). An F-test was used to test whether the standard deviations (SDs) of the two populations were equal or not. To compare the surviving fractions obtained by different experimental conditions, the unpaired Student's t-test and Welch's test were used in the cases where the SDs of two populations were equal or not equal, respectively. Differences were considered significant at $\mathrm{p}<0.05$.

\section{Results}

HIF-1 $\alpha$ expression in A549 cells according to YC-1 modulation. Fig. 2 displays HIF-1 $\alpha$ expression in A549 cells. Cells exposed to hypoxia for both 1 and $24 \mathrm{~h}$ expressed higher levels of HIF-1 $\alpha$ compared with normoxic cells. These expression levels appeared to be similar. In cells exposed to hypoxia for $1 \mathrm{~h}, \mathrm{HIF}-1 \alpha$ expression was suppressed by YC-1 to a similar extent as that observed in YC-1-free normoxic cells.

Role of HIF-1 $\alpha$ in acute hypoxia-induced radioresistance. Fig. 3 shows the results of a clonogenic survival assay of A549 cells irradiated under normoxic conditions without YC-1 and under hypoxic conditions with or without YC-1. The plating efficiency of normoxic and hypoxic cells was 72 and $82 \%$, respectively. There was no significant difference between the plating efficiency of cells exposed to normoxic and hypoxic conditions $(p=0.094)$, demonstrating that exposure to the hypoxic condition of $<0.1 \mathrm{mmHg}$ for $1 \mathrm{~h}$ was not cytotoxic. As shown in Table I, the surviving fractions of A549 cells exposed to hypoxic conditions with or without YC-1 were significantly higher than those exposed to normoxic conditions at any dose point examined ( $\mathrm{p}<0.01,<0.05$ at $2 \mathrm{~Gy} ; \mathrm{p}<0.001$, $<0.001$ at $5 \mathrm{~Gy} ; \mathrm{p}<0.001,<0.001$ at $10 \mathrm{~Gy}$, respectively). Under hypoxic conditions, there was no significant difference between the surviving fraction of cells treated with YC-1 and those without at any dose point examined $(\mathrm{p}=0.17,0.10,0.43$ at 2, 5 and $10 \mathrm{~Gy}$, respectively). The $\mathrm{D}_{10}$ values of normoxic cells without YC-1, hypoxic cells with YC-1 and those without YC-1 were 5.3, 14 and $13 \mathrm{~Gy}$, respectively. Therefore, in the hypoxic groups, the addition of YC-1 did not significantly affect the

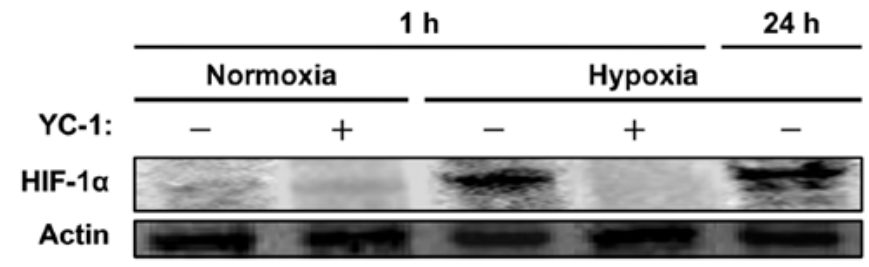

Figure 2. The expression of HIF-1 $\alpha$ in A549 cells. Hypoxic A549 cells were treated with or without YC-1, simultaneously with normoxic A549 cells. The treatment was extended either for 1 or $24 \mathrm{~h}$ followed by preparation of the cells for Western blot analysis. HIF-1 $\alpha$, hypoxia-inducible factor-1 $\alpha$; YC-1, 5-[1-(phenylmethyl)-1H-indazol-3-yl]-2-furanmethanol.

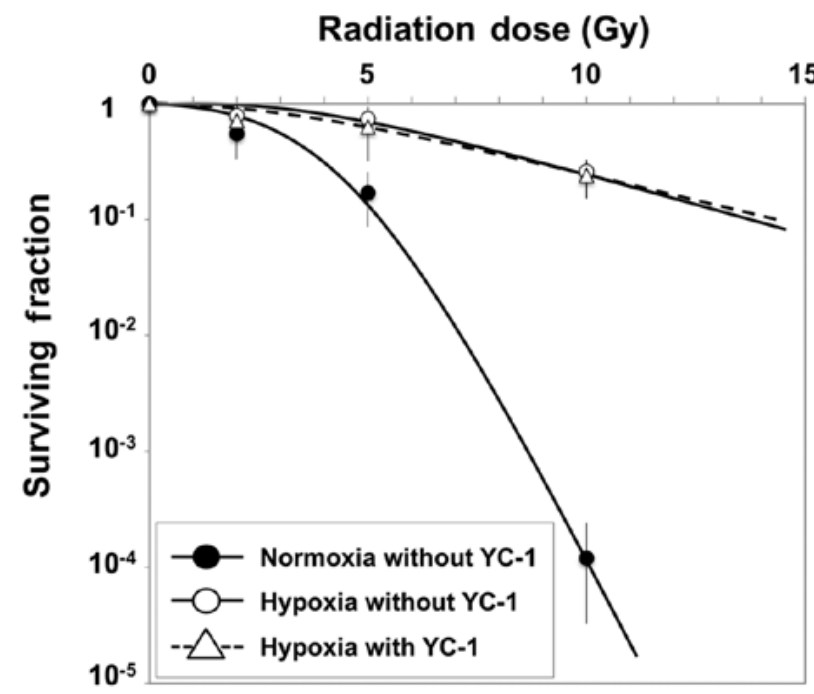

Figure 3. Clonogenic survival curves of A549 cells under normoxic conditions without YC-1 and under a hypoxic condition of $<0.1 \mathrm{mmHg}$ with or without YC-1. Each plot represents an average surviving fraction with the standard deviation obtained from at least three independent experiments. The plots were fitted by the linear-quadratic model using all the data. YC-1, 5-[1-(phenylmethyl)-1H-indazol-3-yl]-2-furanmethanol.

OER value at $10 \%$ surviving fraction in comparison to the YC-1-free medium group (Table I).

\section{Discussion}

In the present study, the radiosensitivity of A549 cells under acute hypoxia was examined in the presence and absence of HIF-1 $\alpha$ expression by suppression of HIF-1 $\alpha$ with YC-1. The 
results showed that the OER in the $10 \%$ surviving fraction was consistent irrespective of HIF-1 $\alpha$ expression.

It has been recognized that, in response to hypoxia, HIF-1 $\alpha$ promotes cell survival by increasing glucose transport, converting cellular metabolism to the obligatory glycolytic system, and also inducing VEGF expression, which leads to angiogenesis (18). However, the exact role of HIF-1 $\alpha$ in hypoxia-induced radioresistance remains unclear. Moreover, to the best of our knowledge, previous studies investigating the relationship between HIF-1 $\alpha$ expression and hypoxia-induced radioresistance do not take into account the different circumstances between acute and chronic hypoxia. In this regard, since the mechanism and clinical significance of radioresistance induced by acute hypoxia have not been fully elucidated, the present study focused on acute hypoxia and investivated whether or not HIF-1 $\alpha$ has a fundamental role in acute hypoxia-induced radioresistance.

In the present study, the OER value of 2.6 obtained in the absence of YC-1 following exposure to hypoxia for $1 \mathrm{~h}$, which is the model for acute hypoxia, was considered to be a value of the typical response of tumor cells to severe hypoxia (8). Meanwhile, HIF-1 $\alpha$ was induced to a similar extent as that following the exposure to hypoxia for $24 \mathrm{~h}$, representing the model for chronic hypoxia. These observations are in accordance with a previous study by Vordermark et al (25). In addition, under acute hypoxia, the expression of HIF-1 $\alpha$ was effectively suppressed by YC-1 (Fig. 2). The exposure to hypoxia for $1 \mathrm{~h}$ was not itself cytotoxic. Taken together, the OER value of 2.7 obtained in the presence of YC-1 clearly indicates that HIF-1 $\alpha$ alone is not an immediate or direct cause of acute hypoxia-induced radioresistance in A549 cells in our experimental system.

There are a number of in vitro studies investigating the effect of HIF-1 $\alpha$ on hypoxia-induced radioresistance. In these reports, cancer cells were subjected to hypoxia for various time periods (25-27). Vordermark et al investigated the correlation between intracellular HIF-1 $\alpha$ levels and radiosensitivity in FaDu and HT1080 cell lines following exposure to hypoxia for $1 \mathrm{~h}$, and found the correlation was only in $\mathrm{FaDu}$ but not in HT1080 cells, suggesting that the correlation between HIF-1 $\alpha$ levels and hypoxia-induced radioresistance is cell-type specific (25). Arvold et al demonstrated that the radiosensitivity of a mouse embryonic fibroblast (MEF) cell line following exposure to hypoxia for $4 \mathrm{~h}$ was independent of HIF-1 $\alpha$ (26), which is in accordance with our results. They compared the radiosensitivity of a HIF-1 $\alpha$-wild-type MEF cell line to that of a HIF-1 $\alpha$-null MEF cell line under hypoxic conditions and showed that the OER of both cell lines in the $10 \%$ surviving fraction was identical. By contrast, Staab et al exposed HT1080 cells to hypoxia for $12 \mathrm{~h}$ with the HIF-1 inhibitor, chetomin, and found that the treatment by chetomin reduced the OER in these cells (27). These results suggest that it is controversial as to whether HIF-1 $\alpha$ plays a fundamental role in hypoxia-induced radioresistance, since a distinction is not made between acute and chronic hypoxia in these studies. Combined with our results, it could be said that the contribution of HIF-1 $\alpha$ to hypoxia-induced radioresistance is low for cells under acute hypoxia or hypoxic conditions for a relatively short time period.

Since the results of the present study reveal that HIF-1 $\alpha$ does not play a direct role in acute hypoxia-induced radioresis- tance, there is a possibility that other proteins that interact with HIF-1 $\alpha$ at higher regulation levels may be involved. In fact, there are some proteins that are considered to be candidates for the cause of radioresistance in response to hypoxia. We also examined the effect of nitric oxide as a factor that regulates hypoxic cells. Nitric oxide showed its ability to regulate HIF-1 $\alpha$ and the epidermal growth factor receptor (EGFR). By adding the nitric oxide synthase (NOS) inhibitor, radiosensitivity was enhanced by the suppression of these two proteins (data not shown). In the present study, exposure to hypoxic conditions for $1 \mathrm{~h}$ increased HIF-1 $\alpha$ expression, as well as exposure to hypoxia for $24 \mathrm{~h}$.

In the microenvironment of solid tumors, hypoxia occurs as a result of the complex interaction of numerous factors, including tumor cells, blood vessels, interstitial tissues and others. Therefore, in vivo investigations would be of great importance to fully understand the exact role of HIF-1 $\alpha$ in acute hypoxia-induced radioresistance. In the literature, there are some in vivo models that would be applicable to the real-time evaluation of intratumoral $\mathrm{pO}_{2}$ and HIF-1 $\alpha$ activity. Cárdenas-Navia et al proved the pervasive presence of acute hypoxia in rat tumor models (12). In their study, phosphorescence lifetime imaging was used to measure fluctuations in vascular $\mathrm{pO}_{2}$ in rat tumors grown in dorsal skin-fold window chambers. Meanwhile, Harada et al demonstrated real-time imaging of intratumoral HIF- $1 \alpha$ activity in tumor xenografts using a cell line expressing luciferase bioluminescence, in conjunction with intracellular accumulation of HIF-1 $\alpha$ protein (28). The combination of these techniques will be beneficial for the simultaneous evaluation of intratumoral $\mathrm{pO}_{2}$ and HIF-1 $\alpha$ activity.

In conclusion, subjecting A549 cells to hypoxia for $1 \mathrm{~h}$ revealed a comparable OER value regardless of HIF-1 $\alpha$ expression. The results indicate that HIF-1 $\alpha$ expression does not contribute primarily to the radiosensitivity of A549 cells under acute hypoxia. Further investigations should be conducted to elucidate the responsible proteins involved in acute hypoxia-induced radioresistance in tumor cells.

\section{References}

1. Brown JM, Wilson WR: Exploiting tumour hypoxia in cancer treatment. Nat Rev Cancer 4: 437-447, 2004.

2. Gatenby RA, Kessler HB, Rosenblum JS, Coia LR, Moldofsky PJ, Hartz WH, et al: Oxygen distribution in squamous cell carcinoma metastases and its relationship to outcome of radiation therapy. Int J Radiat Oncol Biol Phys 14: 831-838, 1988.

3. Kallman RF: The phenomenon of reoxygenation and its implications for fractionated radiotherapy. Radiology 105: 135-412, 1972.

4. Nordsmark M, Overgaard M and Overgaard J: Pretreatment oxygenation predicts radiation response in advanced squamous cell carcinoma of the head and neck. Radiother Oncol 41: 31-39, 1996.

5. Vaupel P, Schlenger K, Knoop C and Höckel M: Oxygenation of human tumors: evaluation of tissue oxygen distribution in breast cancers by computerized $\mathrm{O}_{2}$ tension measurements. Cancer Res 51: 3316-22, 1991.

6. Yeh KA, Biade S, Lanciano RM, Brown DQ, Fenning MC, Babb JS, et al: Polarographic needle electrode measurements of oxygen in rat prostate carcinomas. Int J Radiat Oncol Biol Phys 33: 111-118, 1995.

7. Suzuki Y, Nakano T, Ohno T, Kato S, Niibe Y, Morita S, et al: Oxygenated and reoxygenated tumors show better local control in radiation therapy for cervical cancer. Int J Gynecol Cancer 16: 306-311, 2006. 
8. Hall EJ and Giaccia AJ: Oxygen effect and reoxygenation. In: Radiobiology for the Radiologist. McAllister L (ed). 6th edition. Lippincott Williams \& Wilkins, Philadelphia, PA,pp85-105, 2006.

9. Jain RK: Normalization of tumor vasculature: an emerging concept in antiangiogenic therapy. Science 307: 58-62, 2005.

10. Trotter MJ, Chaplin DJ, Durand RE and Olive PL: The use of fluorescent probes to identify regions of transient perfusion in murine tumors. Int J Radiat Oncol Biol Phys 16: 931-934, 1989.

11. Tufto I and Rofstad EK: Transient perfusion in human melanoma xenografts. Br J Cancer 71: 789-793, 1995.

12. Cárdenas-Navia LI, Mace D, Richardson RA, Wilson DF, Shan S and Dewhirst MW: The pervasive presence of fluctuating oxygenation in tumors. Cancer Res 68: 5812-5819, 2008.

13. Brahimi-Horn MC and Pouysségur J: HIF at a glance. J Cell Sci 122: 1055-1057, 2009.

14. Rankin EB and Giaccia AJ: The role of hypoxia-inducible factors in tumorigenesis. Cell Death Differ 15: 678-685, 2008.

15. Huang LE, Arany Z, Livingston DM and Bunn HF: Activation of hypoxia-inducible transcription factor depends primarily upon redox-sensitive stabilization of its alpha subunit. J Biol Chem 271: 32253-32259, 1996.

16. Hofer T, Desbaillets I, Höpfl G, Gassmann M and Wenger RH: Dissecting hypoxia-dependent and hypoxia-independent steps in the HIF-1 alpha activation cascade: implications for HIF-1 alpha gene therapy. FASEB J 15: 2715-2717, 2001.

17. Chilov D, Camenisch G, Kvietikova I, Ziegler U, Gassmann M and Wenger RH: Induction and nuclear translocation of hypoxiainducible factor-1 (HIF-1): heterodimerization with ARNT is not necessary for nuclear accumulation of HIF-1alpha. J Cell Sci 112: 1203-1212, 1999.

18. Semenza GL: Hypoxia-inducible factor 1 and the molecular physiology of oxygen homeostasis. J Lab Clin Med 131: 207-214, 1998.

19. Xueguan L, Xiaoshen W, Yongsheng Z, Chaosu H, Chunying S and Yan F: Hypoxia inducible factor-lalpha and vascular endothelial growth factor expression are associated with a poor prognosis in patients with nasopharyngeal carcinoma receiving radiotherapy with carbogen and nicotinamide. Clin Oncol 20: 606-612, 2008.
20. Aebersold DM, Burri P, Beer KT, Laissue J, Djonov V, Greiner RH, et al: Expression of hypoxia-inducible factor-1 alpha: a novel predictive and prognostic parameter in the radiotherapy of oropharyngeal cancer. Cancer Res 61: 2911-2916, 2001.

21. Bos R, Zhong H, Hanrahan CF, Mommers EC, Semenza GL, Pinedo HM, et al: Levels of hypoxia-inducible factor-1 alpha during breast carcinogenesis. J Natl Cancer Inst 93: 309-314, 2001.

22. Birner P, Schindl M, Obermair A, Plank C, Breitenecker G and Oberhuber G: Overexpression of hypoxia-inducible factor 1alpha is a marker for an unfavorable prognosis in early-stage invasive cervical cancer. Cancer Res 60: 4693-4696, 2000.

23. Birner P, Gatterbauer B, Oberhuber G, Schindl M, Rössler K, Prodinger A, et al: Expression of hypoxia-inducible factor-1 alpha in oligodendrogliomas: Its impact on prognosis and on neoangiogenesis. Cancer 92: 165-171, 2001.

24. Furusawa Y, Fukutsu K, Aoki M, Itsukaichi H, Eguchi-Kasai K, Ohara $\mathrm{H}$, et al: Inactivation of aerobic and hypoxic cells from three different cell lines by accelerated (3)He-, (12)C- and (20)Ne-ion beams. Radiat Res 154: 485-496, 2000.

25. Vordermark D, Katzer A, Baier K, Kraft P and Flentje M: Cell type-specific association of hypoxia-inducible factor-1 alpha (HIF-1 alpha) protein accumulation and radiobiologic tumor hypoxia. Int J Radiat Oncol Biol Phys 58: 1242-1250, 2004.

26. Arvold ND, Guha N, Wang D, Matli M, Deen DF, Warren RS, et al: Hypoxia-induced radioresistance is independent of hypoxia-inducible factor- 1 in vitro. Int J Radiat Oncol Biol Phys 62: 207-212, 2005

27. Staab A, Loeffler J, Said HM, Diehlmann D, Katzer A, Beyer M, et al: Effects of HIF-1 inhibition by chetomin on hypoxia-related transcription and radiosensitivity in HT 1080 human fibrosarcoma cells. BMC Cancer 7: 213-220, 2007.

28. Harada H, Kizaka-Kondoh S, Itasaka S, Shibuya K, Morinibu A, Shinomiya $\mathrm{K}$, et al: The combination of hypoxia-response enhancers and an oxygen-dependent proteolytic motif enables real-time imaging of absolute HIF-1 activity in tumor xenografts. Biochem Biophys Res Commun 360: 791-796, 2007. 